Supplementary Material:

\title{
Fluorine-specific detection using ICP-MS helps to identify PFAS degradation products in non-targeted analysis
}

\author{
Steffen Heuckeroth ${ }^{1}$, Tengetile N. Nxumalo ${ }^{1}$, Andrea Raab ${ }^{1,2}$, Joerg Feldmann ${ }^{1,2, *}$ \\ ${ }^{1}$ TESLA, Department of Chemistry, University of Aberdeen, Meston Walk, Aberdeen AB24 \\ 3UE, Scotland, UK \\ ${ }^{2}$ TESLA-Analytical Chemistry, Institute of Chemistry, University of Graz, Universitätsplatz 1, \\ 8010 Graz, Austria \\ *Corresponding author: joerg.feldmann@uni-graz.at
}

\section{Table of Content:}

Instrumental parameters:

Table S1: Agilent 8800 ICP-MS/MS parameters.

Table S2: Bruker Daltonics MaXis II ${ }^{\mathrm{TM}}$ parameters.

Table S3: Optimised HPLC gradient for aqueous and organic samples.

Biodegradation experiment

Table S4: Baseline standard deviation in blank measurements in PFOA and 8:2 FTOH elution time windows.

Table S5: Maximum intensities $\left(I_{A}\right)$, background intensities ( $I_{\text {background }}$ ), fluorine concentration $\left(c_{A}\right)$ and background standard deviations $\left(S D_{\text {blank }}\right)$ and determined LOD values determined by formula 1 for PFOA and 8:2 FTOH.

Table S6: LOD values determined by a rule of three approach. 
Control Sample 1 and PFOS background

Figure S1: Peak heights of PFOS in the samples plotted against the sampling day. The numbers represent the incubation experiments according to table 2 .

\section{Control Sample 2}

Alignment of ICP-MS/MS and ESI-MS measurements

Figure S2: Exemplary overlay of the ICP-MS/MS and ESI-MS measurement of the day 7 sample of incubator 3. The maxima of these specific the features are annotated. The average retention time in the ESI-MS was $9.75 \mathrm{~min}$ with a standard deviation of $0.013 \mathrm{~min}$. The ICPMS features showed a stable retention time of $9.53 \mathrm{~min}$.

\section{Consideration of feature broadening effects}

Figure S3: Overlay of a $100 \mathrm{mg}(\mathrm{F}) / \mathrm{L}$ fluorine standard solution measured by ICP-MS/MS and ESI-MS. The retention time of the ESI chromatogram was adjusted by $-0.24 \mathrm{~min}$ to account for the shift described earlier.

\section{ESI-MS Features and ICPMS fluorine detection from biodegradation experiment}

Figure S4: Plot $\mathbf{A}$ shows the extracted ion-chromatograms of feature a and feature $b$, as well as the extracted ion chromatogram of $\mathrm{m} / \mathrm{z} 392.9745$ - 392.9767. Plot B shows the MS1 spectrum during the maximum of feature a, plot $\mathbf{C}$ shows the MS1 spectrum during the maximum of feature $b$. The latter is observed as a fragment of feature $b$ in MS/MS experiment and as an in-source fragment. $\mathrm{m} / \mathrm{z} 392.9745-392.9767$ is observed as a fragment ion in MS/MS experiments of feature $b$ (see figure 3 in manuscript) and as an in-source fragment. On the contrary, feature a does not show any fragment ions and does not show the in-source fragment of $m / z$ 392.97. It does coelute with PFOA, however, as seen in plot $B(m / z 412.9660)$, which has been described as a degradation product of 8:2 FTOH in literature.

Figure S5: Chromatograms of extract incubator 4

Table S7: Features left in the feature list after MZmine filtration steps at fluorine signal from the ICPMS/MS around $6.4 \mathrm{~min}$.

Table S8: ESI-MS analysis of feature a.

Table S9: ESI-MS analysis of feature b. 


\section{Instrumental Parameters}

Table S1: Agilent 8800 ICP-MS/MS parameters

\begin{tabular}{|c|c|c|c|c|}
\hline \multicolumn{2}{|l|}{ [ACQ PARAMETERS] } & & \multicolumn{2}{|l|}{ [MONITOR] } \\
\hline $\begin{array}{l}\text { Acq Mode } \\
\text { Tune Mode \#1: } \\
\text { Sampling Period } \\
\text { Acq Time } \\
\text { Number of Masses }\end{array}$ & $\begin{array}{r}\text { TRA } \\
\text { O2 } \\
0.9905 \mathrm{sec} \\
1199.4955 \mathrm{sec} \\
1\end{array}$ & & $\begin{array}{l}\text { O2 } \\
\text { Mass Pair } \\
\text { (Numerator) } \\
157->157 \\
\end{array}$ & (Denominator) \\
\hline $\begin{array}{l}\text { Element Name } \\
\mathrm{BaF}\end{array}$ & $\begin{array}{l}\text { Monitor } \\
\text { ON }\end{array}$ & $\begin{array}{l}\text { Q1 -> Q2 } \\
157->157\end{array}$ & $\begin{array}{r}\text { IntegTime/Mass [sec] } \\
0.99 \\
\end{array}$ & $\begin{array}{l}\text { Detector Mode } \\
\text { Auto }\end{array}$ \\
\hline \multicolumn{5}{|l|}{ [TUNE] } \\
\hline Tune Way & Custom Tune & & (Lenses) & \\
\hline $\begin{array}{l}\text { Tune Mode \#1: } \\
\text { Scan Type }\end{array}$ & $\begin{array}{r}\mathrm{O} 2 \\
\mathrm{MS} / \mathrm{MS} \\
\end{array}$ & & $\begin{array}{l}\text { Extract } 1 \\
\text { Extract } 2\end{array}$ & $\begin{aligned}-150.0 \mathrm{~V} \\
-8.0 \mathrm{~V}\end{aligned}$ \\
\hline (Plasma) & & & Omega Lens & $22.0 \mathrm{~V}$ \\
\hline $\begin{array}{l}\text { RF Power } \\
\text { RF Matching } \\
\text { Smpl Depth } \\
\text { Nebulizer Gas } \\
\text { Option Gas } \\
\text { Nebulizer Pump } \\
\text { S/C Temp }\end{array}$ & $\begin{array}{r}1600 \mathrm{~W} \\
1.76 \mathrm{~V} \\
7.8 \mathrm{~mm} \\
0.83 \mathrm{l} / \mathrm{min} \\
18.00 \% \\
0.12 \mathrm{rps} \\
2^{\circ} \mathrm{C}\end{array}$ & & $\begin{array}{l}\text { Q1 Entrance } \\
\text { Q1 Exit } \\
\text { Cell Focus } \\
\text { Cell Entrance } \\
\text { Cell Exit } \\
\text { Deflect } \\
\text { Plate Bias }\end{array}$ & $\begin{array}{l}-3.0 \mathrm{~V} \\
0.0 \mathrm{~V} \\
0.0 \mathrm{~V} \\
-60 \mathrm{~V} \\
-135 \mathrm{~V} \\
-50.0 \mathrm{~V} \\
-140 \mathrm{~V} \\
\end{array}$ \\
\hline Gas Switch & Makeup Gas & & & \\
\hline \multirow[t]{2}{*}{ Makeup/Dilution Gas } & $0.40 \mathrm{l} / \mathrm{min}$ & & (Cell) & \\
\hline & & & $\begin{array}{l}\text { Use Gas } \\
\text { He Flow }\end{array}$ & $\begin{array}{r}\text { Yes } \\
\text { Off }\end{array}$ \\
\hline $\begin{array}{l}\text { Q1 Mass Gain } \\
\text { Q1 Mass Offset } \\
\text { Q1 Axis Gain } \\
\text { Q1 Axis Offset } \\
\text { Q1 Bias } \\
\text { Q1 Prefilter Bias } \\
\text { Q1 Postfilter Bias } \\
\end{array}$ & $\begin{array}{r}137 \\
121 \\
1.0006 \\
0.04 \\
-3.0 \mathrm{~V} \\
-10.0 \mathrm{~V} \\
-10.0 \mathrm{~V} \\
\end{array}$ & & $\begin{array}{l}\text { He Flow Rate } \\
\text { H2 Flow } \\
\text { H2 Flow Rate } \\
\text { 3rd Gas Flow } \\
\text { 3rd Gas Flow Rate } \\
\text { 4th Gas Flow } \\
\text { 4th Gas Flow Rate }\end{array}$ & $\begin{array}{r}0.0 \mathrm{ml} / \mathrm{min} \\
\text { Off } \\
0.0 \mathrm{ml} / \mathrm{min} \\
\text { Off } \\
0 \% \\
\text { On } \\
100 \%\end{array}$ \\
\hline Q1 Postfilter Bias & & & OctP Bias & $-62.0 \mathrm{~V}$ \\
\hline $\begin{array}{l}\text { Q2) } \\
\text { Mass Gain }\end{array}$ & 135 & & $\begin{array}{l}\text { OctP RF } \\
\text { Energy Discrimination }\end{array}$ & $\begin{array}{r}200 \mathrm{~V} \\
-10.0 \mathrm{~V} \\
\end{array}$ \\
\hline Mass Offset & 125 & & & \\
\hline Axis Gain & 1.0008 & & (Q2 Ion Guide) & \\
\hline $\begin{array}{l}\text { Axis Offset } \\
\text { QP Bias }\end{array}$ & $\begin{array}{r}-0.05 \\
-72.0 \mathrm{~V}\end{array}$ & & $\begin{array}{l}\text { SLS Factor } \\
\text { SLG Factor }\end{array}$ & $\begin{array}{r}0.5 \\
1\end{array}$ \\
\hline \multicolumn{2}{|l|}{ (EM) } & & (Torch Axis) & \\
\hline Discriminator & $4.2 \mathrm{mV}$ & & Torch $\mathrm{H}$ & $0.6 \mathrm{~mm}$ \\
\hline Analog HV & $1887 \mathrm{~V}$ & & Torch V & $-0.4 \mathrm{~mm}$ \\
\hline \multirow[t]{3}{*}{ Pulse HV } & $1415 \mathrm{~V}$ & & & \\
\hline & & & (Wait Time Offset) & \\
\hline & & & Wait Time Offset & $2 \mathrm{~ms}$ \\
\hline
\end{tabular}


Table S2: Bruker Daltonics MaXis $\|^{\mathrm{TM}}$ parameters.

\begin{tabular}{lr}
\hline Acquisition Parameter & \multicolumn{1}{c}{ Value } \\
\hline Nebuliser & $1.8 \mathrm{bar}$ \\
nanoBooster & $1.80 \mathrm{bar}$ \\
Dry Gas & $4.5 \mathrm{l} / \mathrm{min}$ \\
Dry Heater & $120^{\circ} \mathrm{C}$ \\
Source Type & $\mathrm{ESI}$ \\
Capillary & $3000 \mathrm{~V}$ \\
End Plate Offset & $-650 \mathrm{~V}$ \\
On Volt & $800 \mathrm{~V}$ \\
Target Mass Start & 150 \\
Target Mass End & 1000 \\
\hline
\end{tabular}

Table S3: Optimised HPLC gradient for aqueous and organic samples.

\begin{tabular}{lll}
\hline \multicolumn{3}{c}{$t / \min$} \\
organic & aqueous & $\mathrm{B} / \%$ \\
\hline 0 & 0 & 0 \\
0.5 & 0.5 & 10 \\
4 & 4 & 45 \\
11 & 11 & 100 \\
25 & 13 & 100 \\
25.01 & 13.01 & 0 \\
30 & 18 & 0 \\
\hline
\end{tabular}




\section{Biodegradation Experiment}

\section{Calculation of $L O D$ values}

LOD values are calculated via formula 1.

$$
L O D=3 \cdot S D_{\text {blank }} \cdot \frac{c_{A}}{\left(I_{A}-I_{\text {background }}\right)}
$$

The retention time windows of PFOA and 8:2 FTOH in a calibrant solution were determined. The intensity of $\mathrm{m} / \mathrm{z} 157$ in three blank measurements during these windows was extracted. The standard deviation was determined for each measurement individually and averaged. This describes $S D_{\text {blank }}$ in formula 1.

Table S4: Baseline standard deviation in blank measurements in PFOA and 8:2 FTOH elution time windows.

\begin{tabular}{llllll}
\hline Compound & $\begin{array}{l}\text { Standard } \\
\text { deviation 1 }\end{array}$ & $\begin{array}{l}\text { Standard } \\
\text { deviation 2 }\end{array}$ & $\begin{array}{l}\text { Standard } \\
\text { deviation 3 }\end{array}$ & $\begin{array}{l}\text { Average } \\
\text { deviation }\end{array}$ & standard \\
\hline PFOA & 78.5396408 & 53.2960828 & 75.6337061 & 69.1564765 \\
8:2 FTOH & 157.48531 & 117.86455 & 130.928237 & 135.426032 \\
\hline
\end{tabular}

The maximum intensity of the PFOA and $8: 2 \mathrm{FTOH}$ signal $\left(I_{A}\right)$ was corrected for the background of the baseline in that measurement $\left(I_{\text {background }}\right)$. The background of PFOA and 8:2 $\mathrm{FTOH}$ features was determined as the average of the first and last intensity in the features retention time window (Note that the same retention time window as for the determination of the $\mathrm{S} / \mathrm{N}$ ratio of the blank measurements is used). This describes $I_{A}-I_{\text {background }}$ in the formula above.

The concentrations $\left(c_{A}\right)$ are determined gravimetrically from the weigh-ins and the dilution steps. The volume of the solution was calculated by the density of the solvent methanol $\left(0.792 \mathrm{~g} / \mathrm{cm}^{3}\right)$.

Table S5: Maximum intensities $\left(I_{A}\right)$, background intensities ( $I_{\text {background }}$ ), fluorine concentration $\left(c_{A}\right)$ and background standard deviations $\left(S D_{\text {blank }}\right)$ and determined LOD values determined by formula 1 for PFOA and 8:2 FTOH.

\begin{tabular}{lcclcc}
\hline Compound & $I_{A}$ & $I_{\text {background }}$ & $c_{A} / \mathrm{mg}(\mathrm{F}) / \mathrm{L}$ & $S D_{\text {blank }}$ & $L O D$ \\
\hline PFOA & 2884.9128 & 1191.80554 & 2.75 & 69.1564765 & $0.34 \mathrm{mg} / \mathrm{L}$ \\
8:2 FTOH & 19124.998 & 1237.97559 & 2.73 & 135.426032 & $0.06 \mathrm{mg} / \mathrm{L}$ \\
\hline
\end{tabular}


In case a rule-of-three approach (see formula 2) is taken for the calculation of the LOD based on achieved $\mathrm{S} / \mathrm{N}$ ratios, similar LODs are determined:

$$
L O D=3 \cdot \frac{c_{A}}{\bar{N}_{A}}
$$

Table S6: LOD values determined by a rule of three approach.

\begin{tabular}{llll}
\hline Compound & $c_{A} / \mathrm{mg}(\mathrm{F}) / \mathrm{L}$ & $\mathrm{S} / \mathrm{N}$ & $L O D$ \\
\hline PFOA & 2.75 & 27 & $0.31 \mathrm{mg} / \mathrm{L}$ \\
8:2 FTOH & 2.73 & 121 & $0.07 \mathrm{mg} / \mathrm{L}$ \\
\hline
\end{tabular}

\section{Control Sample 1 and PFOS background}

The final $\mathrm{pH}$ value was 7.0. PFOS was found as a low intensity background signal in the organic extracts of incubator 1 with a maximum intensity of $420 \mathrm{cps}$. The contamination could have originated from the HPLC system, which is why other approaches in the literature add a trapping column behind the mixing chamber. ${ }^{1}$ Since there are no signals in samples of incubation 2 (without sludge), the PFOS signal is more likely to be caused by the sludge itself, as the absence of PFOS in incubation 2 suggests that the FTOH standard is not contaminated with PFOS. Furthermore, this suggests that the sample workup is not the source of the contamination. The PFOS signal was also found in incubation 3 and 4, with similar intensities. The absolute intensities are presented in Figure S1. The trend for incubation 3 and 4 is increasing, but due to the very low count similar to the background in experiment 1 , this should be further investigated by more replicates and a longer overall run time rather than assuming PFOS was formed in the experiment. Since the total intensities are low, PFOS is considered as a background signal for this evaluation.

\section{Control Sample 2}

The final $\mathrm{pH}$ value of was 6.8. The ICP-MS BPC of $\mathrm{m} / z=157$ indicates, that the spiked compound 8:2 FTOH could not be detected throughout the experiment. The samples taken on day 0 and day 1 show irregularities in the baseline, but these can barely be described as a feature. The loss of the compound could be ascribed to evaporation during the experiment due to the poor solubility in water and low boiling point of $113^{\circ} \mathrm{C} .^{2}$ Additionally, the sample was taken below the liquid's surface level, which could be another reason for the poor recovery, 
since 8:2 FTOH is a surface active compound. The ESI-TOF does not detect any signal for 8:2 FTOH in any of the samples of incubator 2 . This result suggests, that for the repetition of this experiment, the best approach could be to use autoclaved sludge for the setup of the sterile control incubator, which would also account for permanent adsorption.

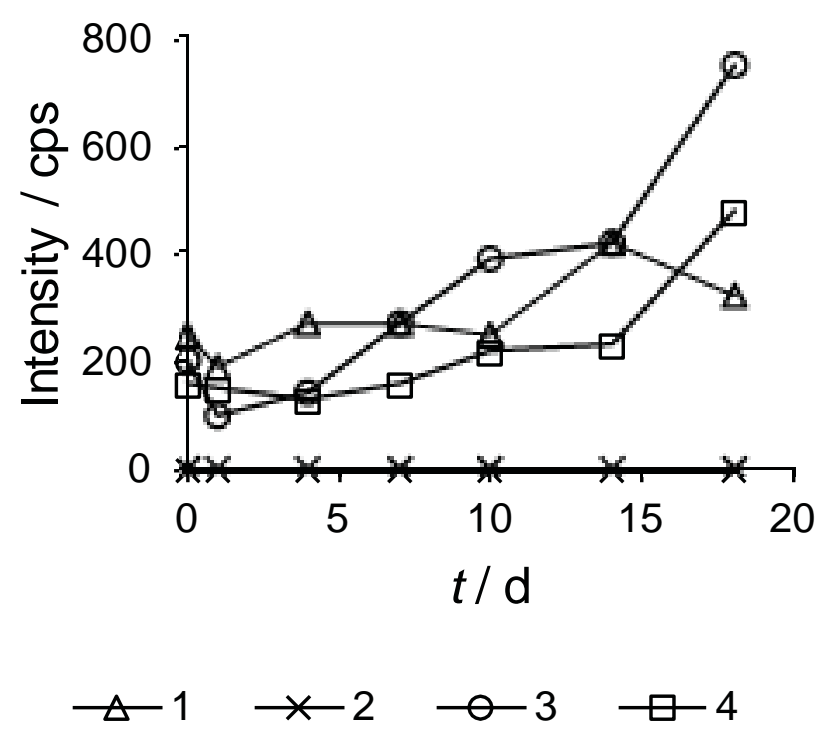

Figure S1: ESI-MS feature heights of PFOS in the samples plotted against the sampling day. The numbers represent the incubation experiments according to table 2 .

\section{Alignment of ICP-MS/MS and ESI-MS measurements}

Alignment of ICP-MS/MS and ESI-MS measurements was accomplished by the signal of 8:2 $\mathrm{FTOH}$, which can be detected with both instruments. A [BaF] ${ }^{+}$signal is detected in the ICP$\mathrm{MS} / \mathrm{MS}$, whereas an $\left[\mathrm{FTOH}+\mathrm{CH}_{3} \mathrm{COO}\right]^{-}$adduct is detected in the ESI-MS. The average retention time in the ESI-MS was 9.75 min with a standard deviation of $0.013 \mathrm{~min}$ and a relative standard deviation of $0.14 \%$. The retention time of $8: 2 \mathrm{FTOH}$ in the ICP-MS measurement was $9.53 \mathrm{~min}$ for all samples. Due to the stable retention times, the window of the retention time filter is shifted for a static offset for all samples. The retention time offset is determined to be $0.24 \mathrm{~min}$. The emerging ICP-MS feature is detected at $6.39 \mathrm{~min}$ (native ICP-MS retention time) and showed no deviation across measurements. Taking the offset of 0.24 min into account, the ESI-MS feature would have to elute at 6.63 minute. To account for the mentioned tailing effects, a relatively wide window of $6.4-7.0$ min was chosen. 


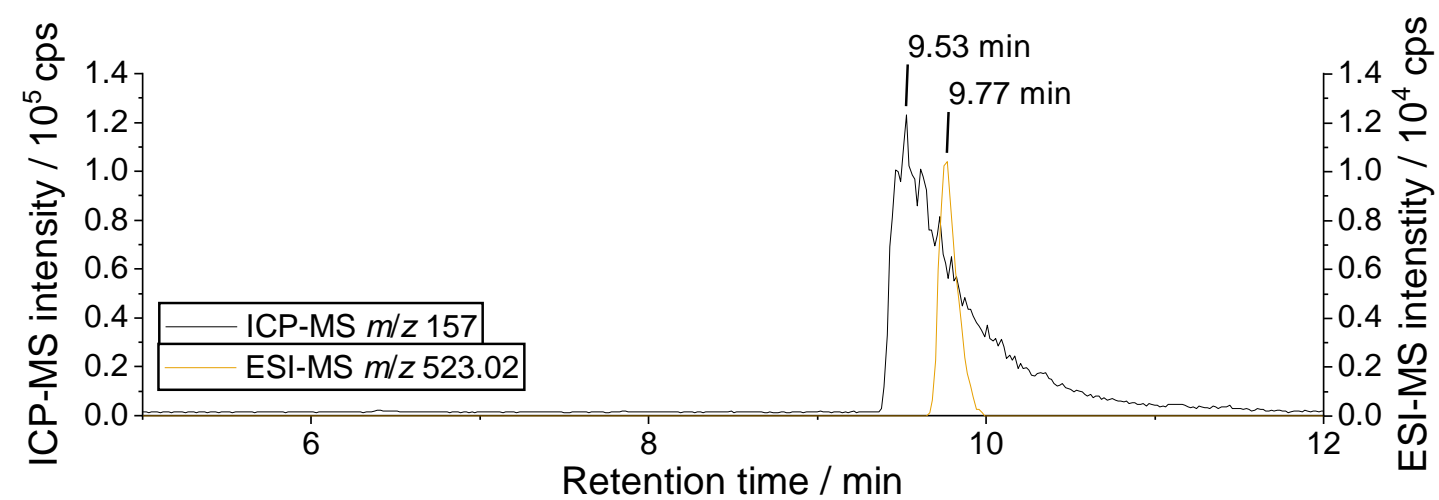

Figure S2: Exemplary overlay of the ICP-MS/MS and ESI-MS measurement of the day 7 sample of incubator 3 . The maxima of these specific the features are annotated. The average retention time in the ESI-MS was $9.75 \mathrm{~min}$ with a standard deviation of $0.013 \mathrm{~min}$. The ICPMS features showed a stable retention time of $9.53 \mathrm{~min}$.

\section{Consideration of feature broadening effects}

As mentioned in the Methods section of the manuscript, feature broadening and tailing is an expected result of flow splitting due to reduced flow rates and increased tubing length. An overlay of the suggested compound 8:2 $\mathrm{FTOH}$ is shown in Figure S2. However, this compound specifically might not be the best model to compare the tailing, because the response of the ESI-MS to 8:2 FTOH is decreased when compared to other compounds, due to instability of the acetate adduct. Therefore, the ESI-MS feature of 8:2 FTOH will not show the same extend of tailing. In contrast, when comparing the chromatograms of PFOA and PFDA, similar shapes are observed (see Figure S3). The ESI-MS chromatogram in Figure S3 is corrected for the offset of 0.24 min., which also shows an appropriate alignment is achieved for the retention time window that was subject to this analysis.

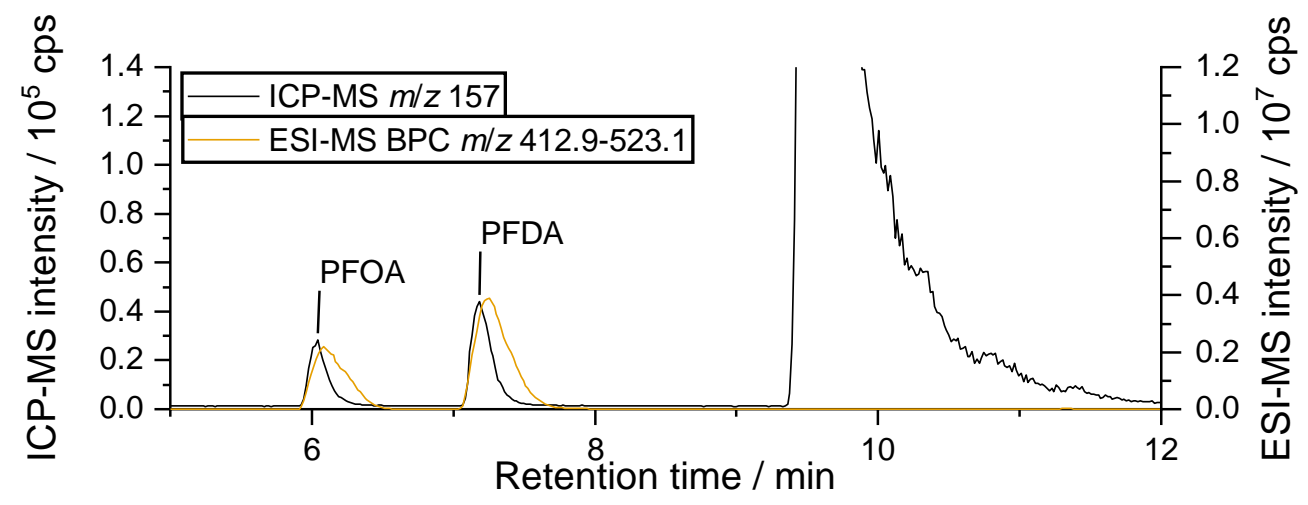

Figure S3: Overlay of a $100 \mathrm{mg}(\mathrm{F}) / \mathrm{L}$ fluorine standard solution measured by ICP-MS/MS and ESI-MS. The retention time of the ESI chromatogram was adjusted by -0.24 min to account for the shift described earlier. 

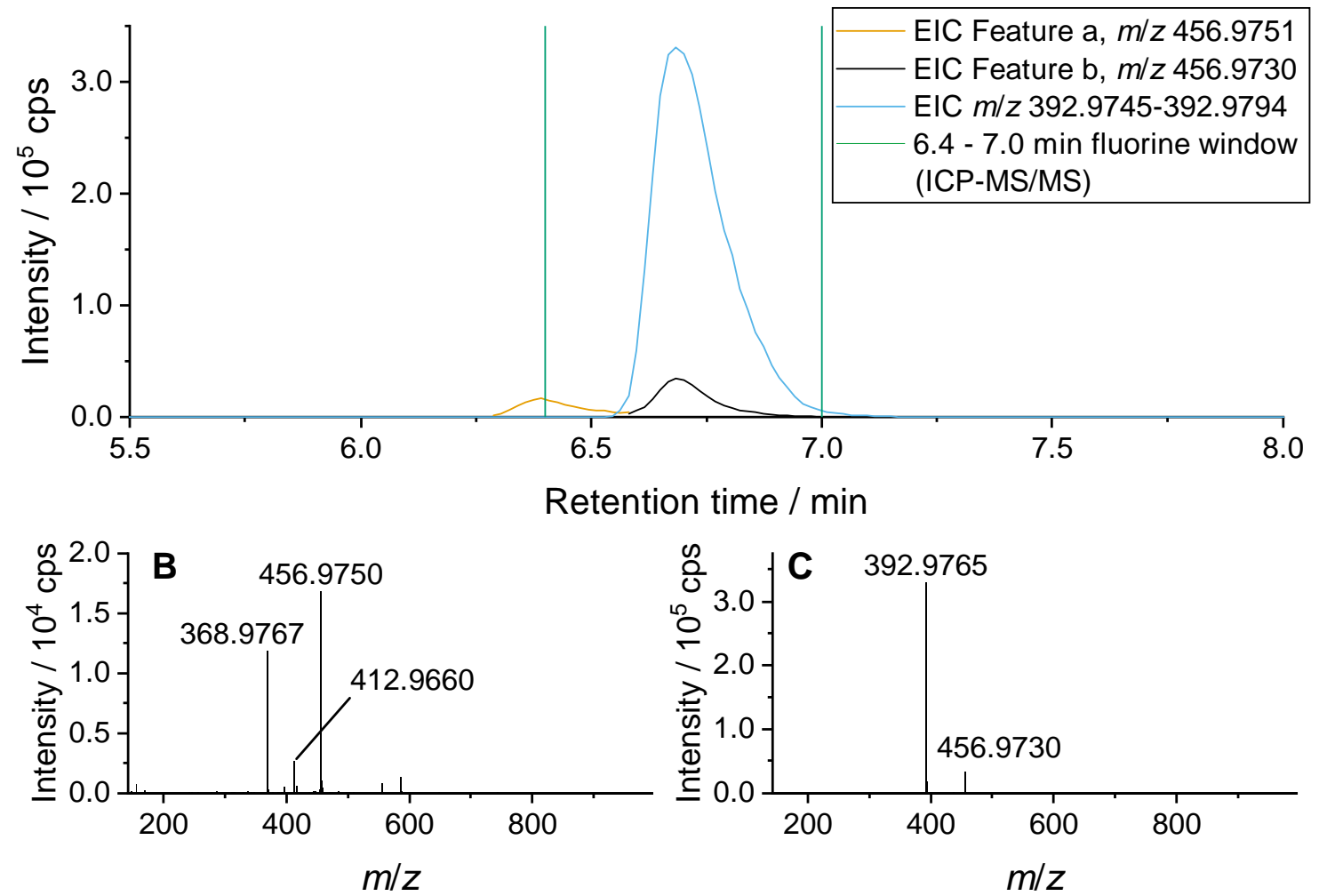

Figure S4: Plot A shows the extracted ion chromatograms of feature a and feature $b$, as well as the extracted ion chromatogram of $\mathrm{m} / \mathrm{z} 392.9745-392.9767$. The fluorine retention time window from 6.4 to $7.0 \mathrm{~min}$ determined by ICP-MS/MS is indicated in by vertical green lines. Plot $\mathbf{B}$ shows the MS1 spectrum during the maximum of feature a, plot $\mathbf{C}$ shows the MS1 spectrum during the maximum of feature $b$. The latter is observed as a fragment of feature $b$ in MS/MS experiment and as an in-source fragment. $\mathrm{m} / \mathrm{z} 392.9745-392.9767$ is observed as a fragment ion in MS/MS experiments of feature $b$ (see figure 3 in manuscript) and as an insource fragment. On the contrary, feature a does not show any fragment ions and does not show the in-source fragment of $\mathrm{m} / \mathrm{z}$ 392.97. It does coelute with PFOA, however, as seen in plot $B(\mathrm{~m} / \mathrm{z} 412.9660)$, which has been described as a degradation product of 8:2 FTOH in literature. ${ }^{3,4}$ 
ESI-MS Features and ICPMS fluorine detection from biodegradation experiment
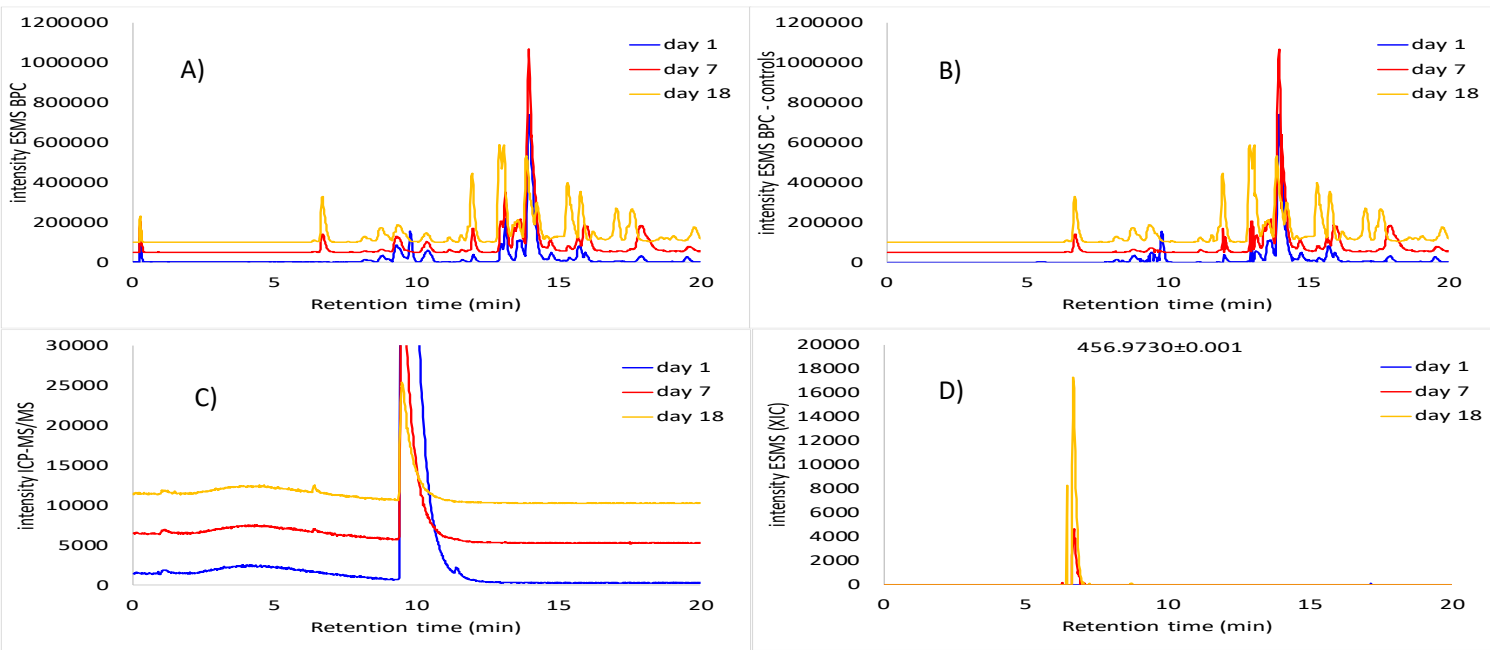

Figure S5: Chromatograms of extract incubator 4. A) total ion counts background corrected (BPC); B) total ion counts background corrected (BPC) minus total ion counts of the control sample (BPC). C) simultaneously recorded ICPMS/MS (m/z $\left.157 \mathrm{BaF}^{+}\right)$and D) extracted ion counts which gives a peak at the same time as the F-peak in C). 
Table S7: Features left in the feature list after MZmine filtration steps at fluorine signal from the ICPMS/MS around $6.4 \mathrm{~min}$.

\begin{tabular}{|c|c|c|c|c|c|}
\hline $\begin{array}{l}\text { Average } \\
\mathrm{m} / \mathrm{z}\end{array}$ & $\begin{array}{l}\text { Average } \\
\mathrm{RT} / \mathrm{min}\end{array}$ & Name & $\begin{array}{l}\text { Average } \\
\text { Height }\end{array}$ & Formula & $\Delta / \mathrm{ppm}$ \\
\hline 456.9749 & 6.39 & 8:2 FTUCA (?) & 6343 & $\mathrm{C} 10 \mathrm{~F} 16 \mathrm{H} 2 \mathrm{O} 2$ & 4.90 \\
\hline 586.0174 & 6.39 & & 630 & & \\
\hline 396.9565 & 6.40 & & 437 & & \\
\hline 416.9629 & 6.40 & & 460 & & \\
\hline 456.9730 & 6.69 & 8:2 FTUCA & 9456 & C10F16H2O2 & 0.79 \\
\hline 457.9764 & 6.69 & & 823 & & \\
\hline 355.1950 & 6.69 & & 293 & & \\
\hline 392.9767 & 6.70 & & 102148 & & \\
\hline 393.9802 & 6.70 & & 5701 & & \\
\hline 242.9864 & 6.70 & & 506 & & \\
\hline 476.9790 & 6.71 & 8:2 FTCA & 710 & C10F17H3O2 & 0.17 \\
\hline 570.9651 & 6.71 & & 274 & & \\
\hline 383.2074 & 6.72 & & 531 & & \\
\hline 497.2000 & 6.74 & & 1546 & & \\
\hline 419.1836 & 6.75 & & 670 & & \\
\hline 446.2028 & 6.76 & & 1818 & & \\
\hline 316.9832 & 6.78 & & 1498 & & \\
\hline 336.9895 & 6.78 & & 1465 & & \\
\hline 438.9821 & 6.85 & 7:3 FTUCA & 9347 & $\mathrm{C} 10 \mathrm{~F} 15 \mathrm{H} 3 \mathrm{O} 2$ & 0.05 \\
\hline 304.9833 & 6.86 & & 361 & & \\
\hline 416.9805 & 6.87 & & 330 & & \\
\hline
\end{tabular}


Table S8: ESI-MS analysis of feature a.

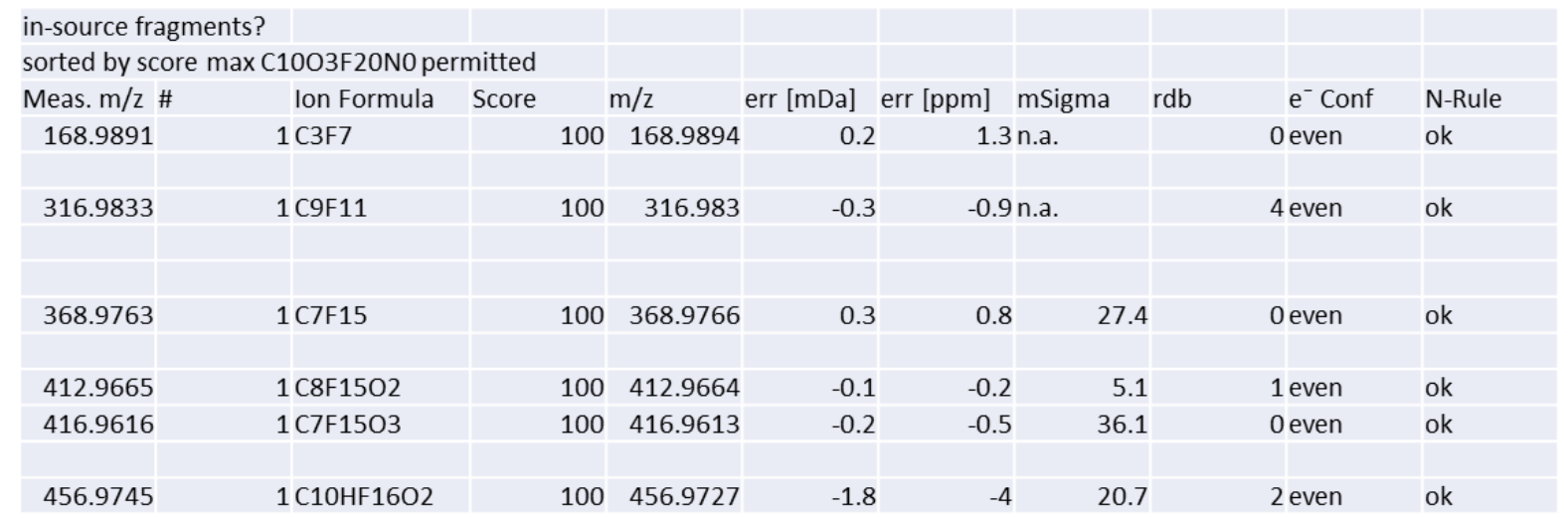

Table S9: ESI-MS analysis of feature b.

\begin{tabular}{|c|c|c|c|c|c|c|c|c|c|}
\hline \multicolumn{10}{|c|}{ in-source fragments? } \\
\hline \multicolumn{10}{|c|}{ sorted by score max C10O3F20N0 permitted } \\
\hline Meas. $\mathrm{m} / \mathrm{z} \#$ & Ion Formula & Score & $\mathrm{m} / \mathrm{z}$ & err [mDa] & err $[\mathrm{ppm}]$ & mSigma & $\mathrm{rdb}$ & $\mathrm{e}^{-}$Conf & N-Rule \\
\hline 242.9862 & 1 C6F9 & 100 & 242.9862 & 0 & -0.2 & 5.2 & & 2 even & ok \\
\hline 316.9829 & 1 C9F11 & 100 & 316.983 & 0.1 & 0.3 & 2.8 & & 4 even & ok \\
\hline 336.9893 & 1 C9HF12 & 100 & 336.9892 & -0.1 & -0.2 & 3.3 & & 3 even & ok \\
\hline 342.98 & $1 \mathrm{C} 8 \mathrm{~F} 13$ & 100 & 342.9798 & -0.2 & -0.5 & n.a. & & 2 even & ok \\
\hline 368.9764 & $1 \mathrm{C} 7 \mathrm{~F} 15$ & 100 & 368.9766 & 0.2 & 0.5 & 12.2 & & 0 even & ok \\
\hline 392.9764 & 1 C9F15 & 100 & 392.9766 & 0.2 & 0.4 & 30.8 & & 2 even & ok \\
\hline 412.9824 & 1 C9HF16 & 100 & 412.9828 & 0.5 & 1.1 & n.a. & & 1 even & ok \\
\hline 438.9821 & $2 \mathrm{C} 10 \mathrm{H} 2 \mathrm{~F} 15 \mathrm{O} 2$ & 100 & 438.9821 & 0 & -0.1 & 29.2 & & 2 even & ok \\
\hline 456.9726 & $1 \mathrm{C} 10 \mathrm{HF} 16 \mathrm{O} 2$ & 100 & 456.9727 & 0 & 0.1 & 26 & & 2 even & ok \\
\hline 476.9788 & $2 \mathrm{C} 10 \mathrm{H} 2 \mathrm{~F} 17 \mathrm{O} 2$ & 100 & 476.9789 & 0.1 & 0.1 & 32.5 & & 1 even & ok \\
\hline
\end{tabular}

\section{References}

(1) Gremmel, C.; Frömel, T.; Knepper, T. P. HPLC-MS/MS methods for the determination of 52 perfluoroalkyl and polyfluoroalkyl substances in aqueous samples. Anal. Bioanal. Chem. 2017, 409 (6), 1643-1655. DOI: 10.1007/s00216-016-0110-z.

(2) SynQuest Laboratories. MSDS No.: 2101324 [Online], FL, USA. http://synquestlabs.com/ msds/2100/2101-3-24.pdf (accessed 2020-02-17).

(3) Wang, N.; Szostek, B.; Buck, R. C.; Folsom, P. W.; Sulecki, L. M.; Gannon, J. T. 8-2 fluorotelomer alcohol aerobic soil biodegradation: pathways, metabolites, and metabolite yields. Chemosphere 2009, 75 (8), 1089-1096. DOI: 10.1016/j.chemosphere.2009.01.033. (4) Dinglasan, M. J. A.; Ye, Y.; Edwards, E. A.; Mabury, S. A. Fluorotelomer alcohol biodegradation yields poly- and perfluorinated acids. Environ. Sci. Technol. 2004, 38 (10), 2857-2864. DOI: 10.1021/es0350177. 